\title{
CLAPHAM Christopher. - The Horn of Africa. State Formation and Decay
}

Alain Gascon

\section{OpenEdition}

Journals

Édition électronique

URL : https://journals.openedition.org/etudesafricaines/27145

DOI : 10.4000 /etudesafricaines. 27145

ISSN : $1777-5353$

\section{Éditeur}

Éditions de l'EHESS

\section{Édition imprimée}

Date de publication : 15 septembre 2019

Pagination : 909-911

ISSN : 0008-0055

\section{Référence électronique}

Alain Gascon, « CLAPHAm Christopher. - The Horn of Africa. State Formation and Decay », Cahiers d'études africaines [En ligne], 235 | 2019, mis en ligne le 15 septembre 2019, consulté le 06 janvier 2022. URL : http://journals.openedition.org/etudesafricaines/27145 ; DOl : https://doi.org/10.4000/ etudesafricaines. 27145

Ce document a été généré automatiquement le 6 janvier 2022

(c) Cahiers d'Études africaines 


\title{
CLAPHAM Christopher. - The Horn of Africa. State Formation and Decay
}

\author{
Alain Gascon
}

\section{RÉFÉRENCE}

CLAPHAM Christopher. - The Horn of Africa. State Formation and Decay. London, Hurst \&

Co., 2017, 224 p., bibl., ill., index.

1 Christopher Clapham, spécialiste reconnu de l'Éthiopie et de la Corne de l'Afrique, relève le défi redoutable d'écrire, en 200 pages, une synthèse analysant l'histoire de la formation et du déclin des États de la région depuis la déposition de Haylä Sellasé (1974), le putsch de Siyaad Barre (1969) et l'indépendance de Djibouti (1977). Pourquoi n'a-t-il pas adopté une transcription plus scientifique des langues éthiopiennes et suivi, en somali, l'orthographe officielle des termes, lieux et patronymes d'autant que, depuis 1972, cette langue est écrite en caractères latins ? Judicieusement, l'auteur a joint, au début du livre, trois cartes: relief, populations et divisions administratives qui introduisent la première partie au titre explicite : The Power of Landscape. À la différence d'autres auteurs, il insiste sur les contraintes de l'étagement du relief pour comprendre la répartition du peuplement et des systèmes de production agricole et agro-pastorale. Une petite réserve : sur une des cartes, les noms des clans-familles (Darood, Issaq) des Somali, certes écrits en italique, risquent d'être confondus avec ceux des peuples (Oromo, Afar). Dommage, en outre, qu'il n'ait pas ajouté une carte de la pluviométrie et du nombre de mois humides. Dans la deuxième partie: Histories of State Creation and Collapse, il est très convaincant quand il montre comment 1991 fut bien l'« année-zéro » de la Corne: la fuite de Mängestu faillit entraîner le démembrement politique de l'Éthiopie tandis que la chute de Siyaad provoqua la division durable de l'État somalien.

Clapham entreprend ensuite l'analyse de chaque État suivant une problématique particulière. En Éthiopie, il met l'accent sur la reconstruction de l'État, en Érythrée sur " la tragédie » (sic.) d'un État post-insurrection, puis sur la gestion des États (au pluriel) 
somali. La conclusion élargit enfin l'analyse à l'échelle du continent et du monde. Avant d'examiner les grands traits de chaque partie, notons que l'auteur a renoncé à considérer les mesures dictatoriales prises en Érythrée comme les péchés de jeunesse d'un État en reconstruction. Je suis réservé quant aux titres des chapitres de sa partie consacrée aux États somali: The Somaliland Option et The Djibouti Anomaly. Leur indépendance, gage de paix, est soutenue par la majorité de leurs citoyens, notamment les Afar qui peuplent la moitié nord de Djibouti où la minorité des Arabes (Yéménites) joue un rôle important. Je suis très surpris quand je lis: "These states, after all, had overwhelmingly been created from the outside, by a European colonialism that had divided the continent through an astonishingly arbitrary process in which indigenous peoples had virtually no part, into territories with artificial boundaries... » (p. 60). Or, la Corne de l'Afrique fournit plusieurs contre-exemples à la «malédiction des frontières africaines ", prêt-à-penser journalistique ${ }^{1}$. L'Éthiopie a échappé à la colonisation et négocié ses frontières alors que les sécessions érythréenne et somalilandaise rétablissent une limite coloniale arbitraire. Ce bref passage n'empêche pas l'auteur de mettre au centre de son analyse les processus de construction, de reconstruction et de destruction de l'État qui renvoient à la question de la nation.

En Éthiopie, la reconstruction a conservé les structures et le personnel administratif de l'État renversé, mais, coiffés par une organisation « léniniste illibérale » (p. 77). Ainsi, le Front démocratique et révolutionnaire du peuple éthiopien (FDRPE) est-il une coalition de partis qui épouse étroitement le caractère ethno-fédéral, à étiquette linguistique, imposé par Mälläs Zénawi. Elle lui fournit une soupape de sécurité à son pouvoir exercé, sans partage, jusqu'à sa mort en 2012. Le conflit avec l'Érythrée (1998-2000) et les élections houleuses de 2005 marquent une double étape dans le mandat de Mälläs. Passé ces deux épreuves, il assuma, par-delà le fédéralisme, l'héritage de l'Éthiopie tout entière et, conscient des faiblesses économiques, décida de se lancer dans une politique de développement administrée " par le haut ». On appela les étrangers à investir dans de vastes concessions agro-industrielles et dans la construction d'infrastructures (barrages, routes, chemins de fer) en vue d'industrialiser le pays à un rythme forcené. Mais ces projets grandioses ont exacerbé les rivalités « ethniques » entre régions, entre villes et campagnes et entre centre et périphéries. "The genie of ethnicity, however, once unleashed could not be put back in its bottle» (p. 107) comme on le vit avec les troubles qui précipitèrent la démission de Haylä Maryam Dässaläñ, le successeur de Mälläs.

En Érythrée, la propension à la dictature d'Isayyas Afäwärqi est plus ancienne que ne le pense Clapham: elle est en effet bien antérieure à la guerre de 1998-2000 et se manifestait déjà alors que celui-ci était dans les maquis.

Chef du Front populaire de libération (FPLE), parti unique - devenu le Front populaire pour la justice et la démocratie (FPJD) - qui est l'État, il est donc lui-même l'État et l'Érythrée et tout opposant est un traître. Obnubilé par les questions de sécurité, il interdit à la jeunesse tout contact avec l'étranger. À part quelques ressources minières, le pays vit en vase clos alimenté par un impôt extorqué, sous la menace, à la diaspora. En Somalie, les candidats à la (re)construction de l'État sont sans doute trop nombreux surtout que s'y ajoutent les acteurs de l'extérieur. L'auteur explore les différents obstacles ethnologiques, politiques, économiques, historiques à l'échec de la gouvernance - dans une société «fluide »- parmi les Somali alors qu'ils parlent tous la même langue, professent l'islam sunnite et partagent les mêmes valeurs culturelles 
et sociales. Faudrait-il peut-être considérer les conséquences profondes sur les Somali des terribles ravages infligés par la dictature de Siyaad Barre ainsi que Nurudinh Farah les décrit dans ses romans?

6 Cette utile synthèse n'échappe pas à une désagréable et pernicieuse habitude qui, chez trop d'auteurs anglo-saxons, confine à une forme de nationalisme incompatible avec l'esprit de la recherche scientifique, la bibliographie ne mentionnant que des ouvrages en anglais. Comme si les langues vernaculaires dans la Corne avaient disparu, comme si, pour être " reconnue », la recherche éthiopisante ou somalisante devait obligatoirement s'exprimer en anglais ${ }^{2}$.

7 Ce livre est paru un an avant les bouleversements survenus dernièrement, avec l'arrivée au pouvoir du nouveau Premier ministre éthiopien, Abiyy Ahmäd. Par une série de mesures spectaculaires, il a entrepris de libéraliser l'État et l'économie, appelé au pouvoir une nouvelle génération et composé un gouvernement où hommes et femmes sont à parité 3 . Il a fait libérer de nombreux prisonniers politiques et autorisé le retour d'opposants en exil. Mais surtout, il a fait la paix avec l'Érythrée, qui a ouvert sa frontière, et conclu des négociations de paix avec les fronts somali d'Ogadén. Contrairement à ce qu'on pourrait penser à première vue, ce livre n'est pas obsolète. Sa lecture est absolument nécessaire à qui désire appréhender la complexité de la situation de la région et la somme d'efforts qu'il faudra mettre en œuvre pour qu'enfin s'y installe une paix durable.

\section{NOTES}

1. M. FOUCHER, Frontières d'Afrique. Pour en finir avec un mythe, Paris, CNRS éditions, 2014 ; A. GASCON, "Menilek II traceur des frontières dans la Corne de l'Afrique", in S. CONSIDÈRE \& T. PERRIN (dir.), Frontières et représentations sociales. Questions et perspectives méthodologiques, Louvain, Academia-L'Harmattan, 2017, pp. 241-265; H. W ESSELING, Le partage de l'Afrique 1880-1914, Paris, Denoël-Folio-Histoire, 1991, 1996.

2. C. Clapham lit le français (témoignage personnel).

3. L'élection à la présidence fédérale de Sahlä Wärq Zäwdé, une diplomate chevronnée, confirme ce renouveau. 